\title{
Profile of Urinary Tract Infections and Resistance Patterns in a Tertiary Care Hospital in India
}

\author{
D. Maheswary* and Chitralekha Saikumar
}

Department of Microbiology, Sree Balaji Medical College, Chrompet, Chennai 44, India

*Corresponding author

\section{A B S T R A C T}

\section{Keywords}

Antimicrobial resistance,

Resistance patterns

Article Info

Accepted:

07 February 2018

Available Online:

10 March 2018
Antimicrobial resistance to urinary tract pathogens has been on steady rise worldwide. Community-acquired urinary tract infections (CA-UTI) are treated empirically based on their antimicrobial resistance patterns in a population of specific geographical location. Given the increased resistance of community bacteria to antimicrobials, local knowledge of susceptibility rates of uropathogens is essential for therapeutic decision making regarding patients with urinary tract infections.

\section{Introduction}

Urinary tract infection (UTI) is one of the common infections worldwide which are more common in women than in men (Mihankhah Abbas et al., 2017). It remains a major public health problem in terms of morbidity with an estimated 150 million cases annually worldwide, costing global economy in excess of 6 billion US dollars (Gonzalez and Schaeffer, 1999). UTI is defined as presence of bacteria in urine along with urinary symptoms like dysuria, frequency, urgency and occasionally suprapubic tenderness (Dash Muktikesh et al., 2013). It may involve the lower or upper urinary tract. UTI occurring in premenopausal and non-pregnant women and in people with no known urological abnormalities are classified as uncomplicated, while others are considered complicated UTI (Hsueh et al., 2011).

UTIs to a great extent are caused by Gramnegative bacteria, like Escherichia coli, Proteus mirabilis, Klebsiella pneumoniae, Pseudomonas aeruginosa, Enterobacter spp. UTI'S are also caused by gram positive organisms like Group B Streptococcus and Staphylococcus saprophyticus and Enterococcus spp (Saadeh and Mattoo, 2011).

Differences in microbial spectrum and susceptibility patterns may occur in different regions, and the knowledge of antimicrobial use serves as an important predictor of resistance (Kiffer et al., 2011). 
Some Enterobacteriaceae are resistant to nearly all antibiotics, including carbapenems, which are often considered the antibiotics of last resort (Centers for Disease Control and Prevention, 2013). More than 9,000 healthcare-associated infections are caused by CRE each year. Each year, approximately 600 deaths result from infections caused by the two most common types of CRE, carbapenemresistant Klebsiella spp. and carbapenemresistant E. coli (Centers for Disease Control and Prevention, 2013). CA-UTIs are treated empirically, in most of the situations. Hence the choice of appropriate antimicrobial agents should be determined by the most likely pathogen isolated and their resistance pattern in a geographic area. Therefore there is need for periodic monitoring of etiologic agents of UTI, and their resistance pattern in the community.

\section{Materials and Methods}

The present retrospective study was carried out in the central clinical microbiology laboratory of a tertiary care hospital in Tamilnadu, India and catering patients mostly from rural areas. The duration of the study was 10 months from Feb 2017 to December 2017.

\section{Study population}

A total of 644 adult patients with signs to symptoms of UTI who attended the outpatient departments (OPDs) and inpatients of our hospital were recruited for this study. Verbal informed consent was obtained from all patients prior to specimen collection. The study was conducted after due approval from institutional ethical committee.

\section{Sample collection and processing}

Freshly voided, clean-catch midstream urine sample were collected from patients in sterile screw-capped universal container. The specimen was labeled and transported to the microbiology laboratory for processing within $2 \mathrm{~h}$. Semi quantitative urine culture was done using a calibrated loop. A loopful $(0.001 \mathrm{~mL})$ of well mixed un-centrifuged urine was inoculated in cysteine lactose electrolyte deficient medium and Blood agar. The culture plates were incubated aerobically at $37^{\circ} \mathrm{C}$ for 18-24 $\mathrm{h}$ and count were expressed as colony forming units (cfu) per milliliter (ml). For this study, significant bacteriuria was defined as culture of a single bacterial species from the urine sample at a concentration of $10^{5} \mathrm{cfu} / \mathrm{ml}$ associated with microscopy findings of $>10$ white blood cells (WBCs) per high power field. (Kass, 1957) Only patients with significant bacteriuria $\left(\geq 10^{5} \mathrm{cfu} / \mathrm{ml}\right)$ were included for microbiological analysis. The culture isolates were identified by standard microbiological methods (Collee et al., 2006). All culture media were procured from HiMedia Laboratories, Mumbai, India.

Isolates were tested for antimicrobial susceptibility testing by the standard KirbyBauer disc diffusion method according to Bauer et al., (1966). Mueller-Hinton agar plates were incubated for $24 \mathrm{~h}$ after inoculation with organisms and placement of discs. After $24 \mathrm{~h}$ the inhibition zones were measured. The following standard antibiotic discs for the isolates were used; ampicillin (10 $\mathrm{mcg})$, augmentin i.e. amoxicillin + clavulinic acid (20/10 mcg), co-trimoxazole (23.75/1.25 $\mathrm{mcg}$ ), nitrofurantoin (300 $\mathrm{mcg}$ ), ciprofloxacin (5 mcg), ofloxacin $(5 \mathrm{mcg})$, cefaclor $(30 \mathrm{mcg})$, cefpodoxime cefpodoxime proxetil $(10 \mathrm{mcg})$, gentamicin $(10 \mathrm{mcg})$ and amikacin $(30 \mathrm{mcg})$. Antibiotic discs were obtained from HiMedia Laboratories, Mumbai, India. The results were interpreted according to Clinical and Laboratory Standards Institute guidelines. (Clinical and Laboratory Standards Institute, 2016) The quality control strains used were $E$. coli American type culture collection (ATCC) 
25922, Pseudomonas aeruginosa ATCC 27853, Enterococcus fecalis ATCC 29212 and Staphylococcus aureus ATCC 25923 for antimicrobial discs.

\section{Results and Discussion}

From a total of 644 urine samples collected from CA-UTI patients 409 (63.51\%) yielded significant pathogens. A significantly low value of $39.7 \%$ was obtained by Oladeinde $e t$ al., in a community in Nigeria (Oladeinde $e t$ al., 2011). The culture positive rate for CAUTI was higher in our study in comparison with other studies conducted in India $(17.19 \%)$ and Aligarh, India (10.86\%). (Oladeinde et al., 2011; Akram et al., 2007) Geographical location may be the reason for this wide difference.

The finding showed that females (63.51\%) had higher prevalence of UTI in comparison with males $(30.32 \%)$ which is in agreement with other previous studies (Oladeinde et al., 2011; Akram et al., 2007; Kashef et al., 2010). Presence of a short urethra, situation of the female urethral meatus in close proximity to anus and increased frequency of sexual intercourse in middle age group women have been reported as factors contributing to higher prevalence in women (Omoregie et al., 2008).

The age group analysis showed that young female patients in the range of 20-35 years had highest prevalence rate $(31.05 \%)$ of CA-UTI which is in agreement with previous studies (Akram et al., 2007; Hooton et al., 1996). The incidence of UTI is quite high among sexually active young women which is strongly related to recent use of diaphragm with spermicide and history of recurrent UTIs (Khameneh and Afshar, 2009). Studies have shown that the incidence of UTI increases among males due to prostate enlargement and neurogenic bladder. This study showed a higher incidence of UTI (14.43\%) in elderly males ( $\geq 60$ years) in comparison to the elderly females $(5.13 \%)$ In a study conducted by Sood et al., similar results were seen (Hooton et al., 1996). In this study Gram-negative bacteria $(73.75 \%)$ were isolated predominantly among which $E$. coli was the commonest uropathogen accounting for $33.49 \%$ of all culture-positive isolates. About $19.8 \%$ of isolates were Klebsiella spp. in this study. The percentage of bacterial species isolated in other studies also showed similar results (Hooton et al., 1996; GarcíaMorúa et al., 2009). In a study conducted by Garcia-Morŭa et al., showed that E. coli was the commonest organism in UTI (24.7\%), followed by Candida albicans (23.7\%) among Mexican population group (Das et al., 2006). Members of Enterobacteriaceae colonize the urogenital mucosa with adhesins, pili, fimbriae, and P-1 blood group phenotype receptor (Gupta et al., 2011).

The infectious disease society of America guidelines considers co-trimoxazole, fluoroquinolones, nitrofurantoin, and $\beta$ lactams as current standard empirical therapy for uncomplicated UTI in women (Kothari and Sagar, 2008). However in developing countries like India antimicrobial susceptibility patterns and antibiotic policies must be considered before choosing an antibiotic for treatment. Uncomplicated UTIs are frequently treated empirically with oral antibiotics. Urine culture and antibiotic susceptibility testing are conducted only during treatment failure, recurrence or relapsing infection.

In our study among Gram-negative bacteria, E. coli showed high level of resistance to frequently used antibiotics like $\beta$-lactams (ampicillin, augmentin, cefaclor, and cefpodoxime), fluoroquinolones (ciprofloxacin and ofloxacin) and cotrimoxazole (Hooton et al., 1996; Larsson et al., 2000) (Table 1 and 2). 
Table.1 Effect of gender on prevalence of urinary tract infection

\begin{tabular}{l|l|}
\hline Gender \\
\hline Male \\
\hline Female \\
\hline Total \\
\hline
\end{tabular}

\begin{tabular}{|l|l|l|}
\hline \multirow{2}{*}{ No. tested } & \multicolumn{2}{|l|}{ Total No. of urine specimen } \\
\cline { 2 - 3 } & No. infected & No. not infected \\
\hline 209 & 124 & 85 \\
\hline 435 & 285 & 150 \\
\hline 644 & 409 & 235 \\
\hline
\end{tabular}

Table.2 Profile of uropathogens isolated in mono microbial cultures $(\mathrm{N}=409)$

\begin{tabular}{|c|c|c|c|}
\hline S. No & Organism isolated & Total Numbers & Percentage \\
\hline $\mathbf{1 .}$ & Escherichia coli & 137 & 33.49 \\
\hline $\mathbf{2 .}$ & Klebsiella spp & 81 & 19.8 \\
\hline $\mathbf{3 .}$ & Pseudomonas spp & 43 & 10.51 \\
\hline $\mathbf{4 .}$ & Proteus spp & 40 & 9.77 \\
\hline $\mathbf{5 .}$ & Enterococcus spp & 31 & 7.57 \\
\hline $\mathbf{6 .}$ & Staphylococcus aureus & 35 & 8.56 \\
\hline $\mathbf{7 .}$ & Candida spp & 22 & 5.38 \\
\hline $\mathbf{8 .}$ & Streptococcus spp & 20 & 4.89 \\
\hline
\end{tabular}

Chart.1 Age wise distribution on prevalence of urinary tract infection

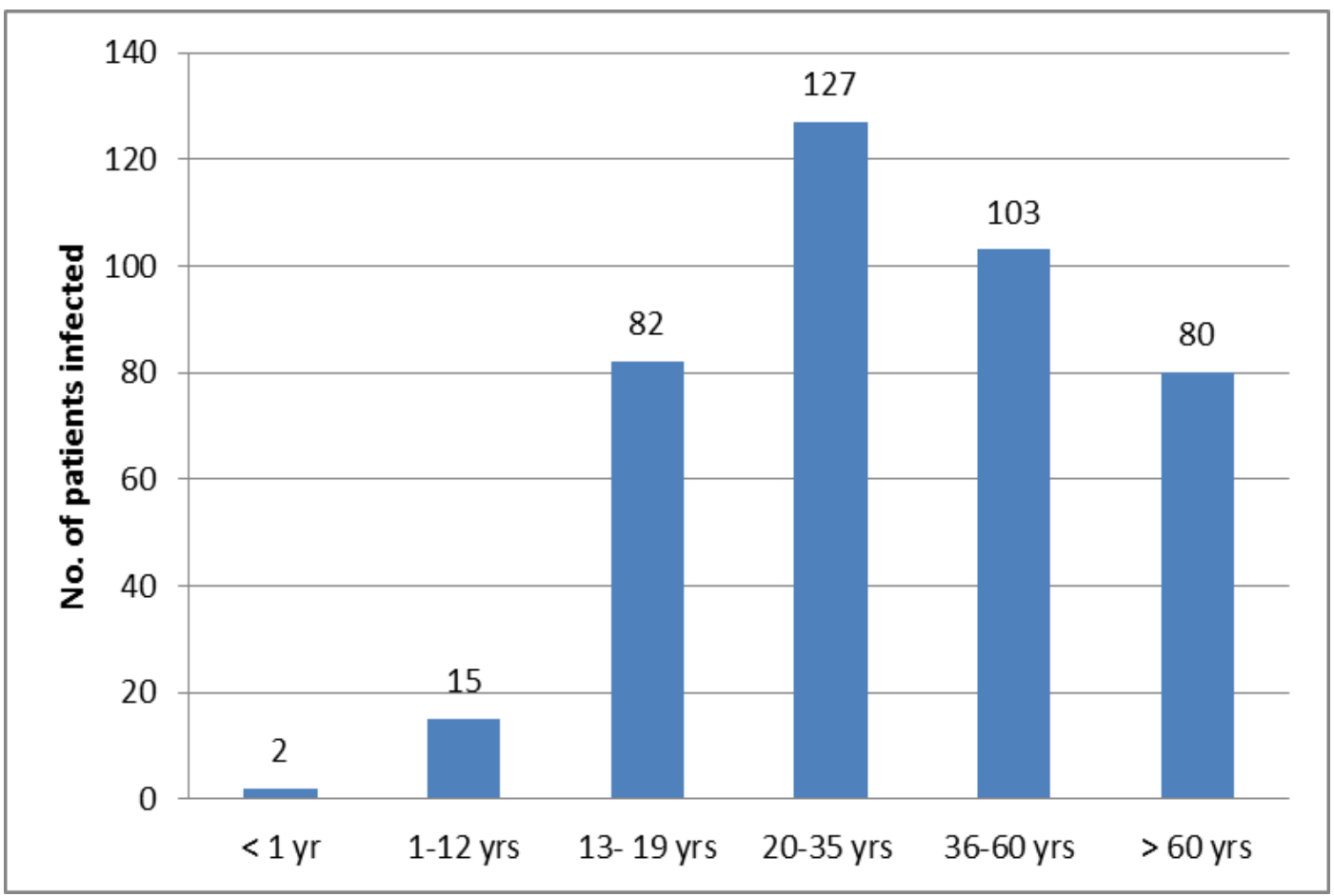


Chart.2 Resistance patterns of Escherichia coli and other Gram-negative isolates

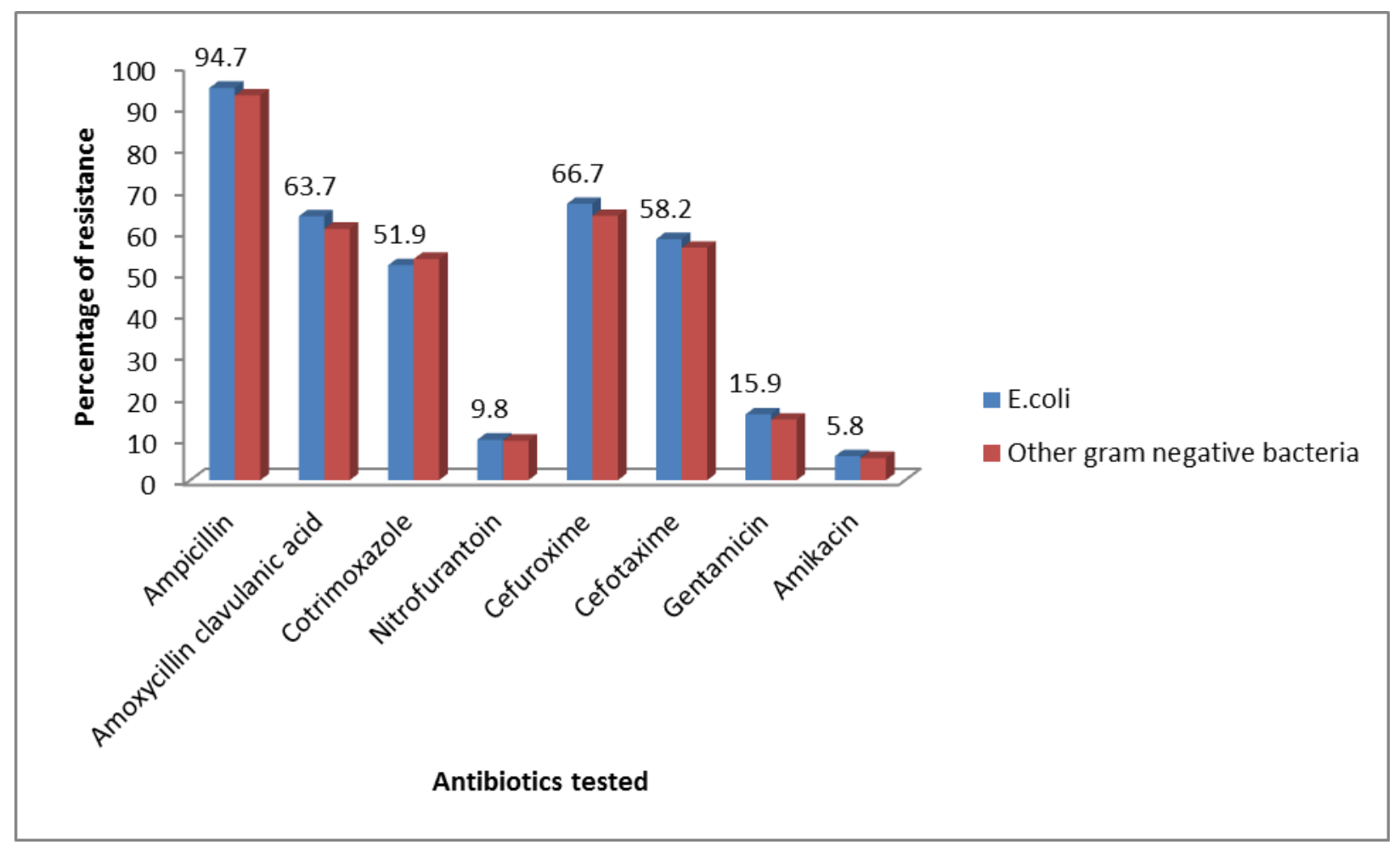

The high resistant rates among the uropathogens could be due to indiscriminate use of antimicrobials by private practitioners, pharmacists and nurses, inappropriate dosing and short course of therapy with antibiotics. Availability of over the counter drugs all over the country has played an important role for this widespread resistance in antibiotics. The widespread use of antimicrobials in Farming animals may be another factor for the emergence of resistant strains as reported in enterococcus.

Gentamicin and Amikacin showed resistant rates of $15.9 \%$ and $5.8 \%$, respectively for $E$. coli among the aminoglycosides.

In this study, less than $10 \%$ resistance has been shown by nitrofurantoin with superior activity to most uropathogens and hence can be considered as a choice for treating uncomplicated UTI. Nitrofurantoin being an oral antibiotic can be used in community and rural settings. Low rates of resistance have also been reported from studies conducted in various regions throughout India (Hooton et al., 1996; Shaifali et al., 2012). Therapy with Nitrofurantoin has limited usage in treating complicated UTI and in elderly patients (Vasquez and Hand, 2004).

Urinary tract infections are common in females when compared with males and the commonest uropathogen isolated was Escherichia coli. Gram negative isolates were isolated predominantly showing resistance to most of the antibiotics. International guidelines of treatment of guidelines cannot be applied in developing country like India.

Hence proper antibiotic policies must be formulated and followed to curb the antibiotic resistance. Treatment must be started based on culture reports and resistance patterns reported in specific location. 


\section{References}

Akram M, Shahid M, Khan AU. Etiology and antibiotic resistance patterns of community-acquired urinary tract infections in J N M C Hospital Aligarh, India. Ann Clin Microbiol Antimicrob 2007; 6: 4.

Bauer AW, Kirby WM, Sherris JC, Turck M. Antibiotic susceptibility testing by a standardized single disk method. Am J Clin Pathol. 1966; 45: 493-6.

Centers for Disease Control and Prevention, Office of Infectious Disease Antibiotic resistance threats in the United States, 2013. Apr, 2013. Available at: http://www.cdc.gov/drugresistance/thre at-report-2013. Accessed January 28, 2015

Clinical and Laboratory Standards Institute. CLSI document M100-S19. Wayne, PA: USA: Clinical and Laboratory Standards Institute; 2016. Performance standards for antimicrobial susceptibility testing: Nineteenth Informational Supplement.

Collee JG, Miles RS, Watt B. Tests for identification of bacteria. In: Collee JG, Fraser AG, Marmion BP, Simmons A, editors. Mackie and Mc Cartney Practical Medical Microbiology. 14th ed. Singapore: Churchill Livingstone; 2006. pp. 131-49.

Das RN, Chandrashekhar TS, Joshi HS, Gurung M, Shrestha N, Shivananda PG. Frequency and susceptibility profile of pathogens causing urinary tract infections at a tertiary care hospital in western Nepal. Singapore Med J. 2006; 47: 281-5.

Dash Muktikesh, et al., "Antimicrobial Resistance in Pathogens Causing Urinary Tract Infections in a Rural Community of Odisha, India." Journal of Family \& Community Medicine 20.1 (2013): 20-26. PMC.
García-Morúa A, Hernández-Torres A, Salazar-de-Hoyos JL, Jaime-Dávila R, Gómez-Guerra LS. Communityacquired urinary tract infection etiology and antibiotic resistance in a Mexican population group. Rev Mex Urol. 2009; 69: 45-8.

Gonzalez CM, and Schaeffer AJ. Treatment of urinary tract infection: What's old, what's new, and what works. World J Urol. 1999; 17: 372-82.

Gupta K, Hooton TM, Naber KG, Wullt B, Colgan R, Miller LG, et al., International clinical practice guidelines for the treatment of acute uncomplicated cystitis and pyelonephritis in women: A 2010 update by the Infectious Diseases Society of America and the European Society for Microbiology and Infectious Diseases. Clin Infect Dis. 2011; 52: e103-20.

Hooton TM, Scholes D, Hughes JP, Winter C, Roberts PL, Stapleton AE, et al., A prospective study of risk factors for symptomatic urinary tract infection in young women. N Engl J Med. 1996; 335: 468-74.

Hsueh PR, Hoban DJ, Carmeli Y, Chen SY, Desikan S, Alejandria $\mathrm{M}$, et al., Consensus review of the epidemiology and appropriate antimicrobial therapy of complicated urinary tract infections in Asia-Pacific region. J Infect. 2011; 63: 114-23.

Kashef N, Djavid GE, Shahbazi S. Antimicrobial susceptibility patterns of community-acquired uropathogens in Tehran, Iran. J Infect Dev Ctries. 2010; 4: 202-6.

Kass EH. Bacteriuria and the diagnosis of infections of the urinary tract; with observations on the use of methionine as a urinary antiseptic. AMA Arch Intern Med. 1957; 100: 709-14. 
Khameneh ZR, and Afshar AT. Antimicrobial susceptibility pattern of urinary tract pathogens. Saudi J Kidney Dis Transpl. 2009; 20: 251.

Kiffer CR, Camargo EC, Shimakura SE, Ribeiro PJ Jr, Bailey TC, Pignatari AC, et al., A spatial approach for the epidemiology of antibiotic use and resistance in community-based studies: the emergence of urban clusters of Escherichia coli quinolone resistance in Sao Paulo, Brasil. Int J Health Geogr. 2011; 10: 17.

Kothari A, and Sagar V. Antibiotic resistance in pathogens causing communityacquired urinary tract infections in India: A multicenter study. J Infect Dev Ctries. 2008; 2: 354-8.

Larsson M, Kronvall G, Chuc NT, Karlsson I, Lager F, Hanh HD, et al., Antibiotic medication and bacterial resistance to antibiotics: A survey of children in a Vietnamese community. Trop Med Int Health. 2000; 5: 711-21.

Mihankhah Abbas, et al., "Prevalence and Antibiotic Resistance Pattern of Bacteria Isolated from Urinary Tract
Infections in Northern Iran." Journal of Research in Medical Sciences: The Official Journal of Isfahan University of Medical Sciences 22 (2017): 108.

Oladeinde BH, Omoregie R, Olley M, Anunibe JA. Urinary tract infection in a rural community of Nigeria. $\mathrm{N}$ Am J Med Sci. 2011; 3: 75-7.

Omoregie R, Erebor JO, Ahonkhai I, Isobor $\mathrm{JO}$, Ogefere HO. Observed changes in the prevalence of uropathogens in Benin City, Nigeria. NZJ Med Lab Sci. 2008; 62: 29-31.

Saadeh SA, and Mattoo TK. Managing urinary tract infections. Pediatr Nephrol. 2011; 26: 1967-76.

Shaifali I, Gupta U, Mahmood SE, Ahmed J. Antibiotic susceptibility patterns of urinary pathogens in female outpatients. N Am J Med Sci. 2012; 4: 163-9.

Vasquez Y, and Hand WL. Antibiotic susceptibility patterns of community acquired urinary tract infection isolates from female patients on the US (Texas)Mexico Border. J Appl Res. 2004; 4: $321-6$.

\section{How to cite this article:}

Maheswary, D. and Chitralekha Saikumar. 2018. Profile of Urinary Tract Infections and Resistance Patterns in a Tertiary Care Hospital in India. Int.J.Curr.Microbiol.App.Sci. 7(03): 506-512. doi: https://doi.org/10.20546/ijcmas.2018.703.060 